\title{
WestVirginiaUniversity
}

THE RESEARCH REPOSITORY @ WVU

Graduate Theses, Dissertations, and Problem Reports

2021

\section{The Joyful Path of Lifelong Mastery of the Piano}

John Alan Rose

West Virginia University, jar0079@mix.wvu.edu

Follow this and additional works at: https://researchrepository.wvu.edu/etd

Part of the Music Performance Commons, and the Music Practice Commons

\section{Recommended Citation}

Rose, John Alan, "The Joyful Path of Lifelong Mastery of the Piano" (2021). Graduate Theses,

Dissertations, and Problem Reports. 8056.

https://researchrepository.wvu.edu/etd/8056

This Dissertation is protected by copyright and/or related rights. It has been brought to you by the The Research Repository @ WVU with permission from the rights-holder(s). You are free to use this Dissertation in any way that is permitted by the copyright and related rights legislation that applies to your use. For other uses you must obtain permission from the rights-holder(s) directly, unless additional rights are indicated by a Creative Commons license in the record and/ or on the work itself. This Dissertation has been accepted for inclusion in WVU Graduate Theses, Dissertations, and Problem Reports collection by an authorized administrator of The Research Repository @ WVU.

For more information, please contact researchrepository@mail.wvu.edu. 
The Joyful Path of Lifelong Mastery of the Piano

John Alan Rose

Research project submitted to the College of Creative Arts at West Virginia University

In partial fulfillment of the requirements for the degree of

Doctor of Musical Arts

in Piano Performance

\author{
Peter Amstutz, DMA, Chair \\ Lucy Mauro, DMA \\ Matthew Heap, PhD \\ Beth Royall, MLIS, MM
}

School of Music

Morgantown, West Virginia

2021

Keywords: Pianist's Handbook, Practical, Practice, Joy

Copyright (C2021 by John Alan Rose

All rights reserved 


\section{Abstract \\ The Joyful Path of Lifelong Mastery of the Piano}

\section{John Alan Rose}

Designed to function as a handbook for pianists, this research project is written in a friendly manner. Organized by theme, it contains a multiplicity of approaches that pianists at all levels can apply to their daily piano practice to help deepen the meaning and efficacy of their work. No matter what role the piano plays in your life, there is much in this document that will help you find joy as you discover new things about yourself through practicing the piano. From methods of practice to philosophies by established performers, this project has enough material to be kept within arm's reach of the instrument. 


\section{Acknowledgments}

Thank you to my Family for your constant and loving support of my musical path in life. Thank you, Grandma Ballard, for the magical worlds we explored in music as you taught me in my childhood. Thank you, Anthony Picchi, for pushing me to grow in new ways as a young pianist in high school. Thank you, Randy Mangus, for your friendship and for mentoring me as a piano technician. Thank you, David Wehr and Peter Amstutz, for playing such important roles in my graduate studies in piano. Thank you, Hsing-Yi, for making this path of music and life so joyful. 


\section{Table of Contents}

Abstract ii

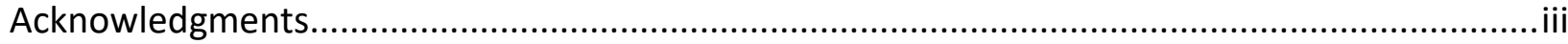

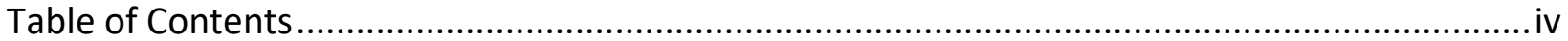

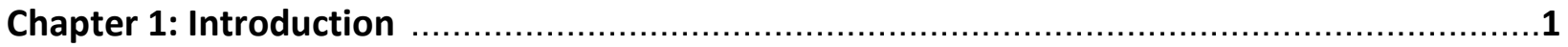

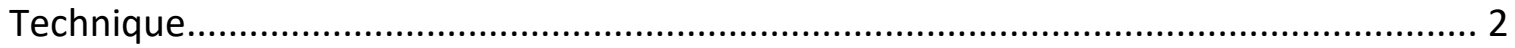

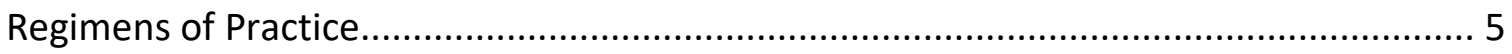





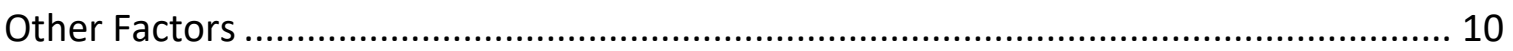

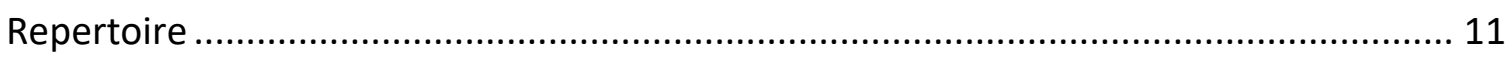

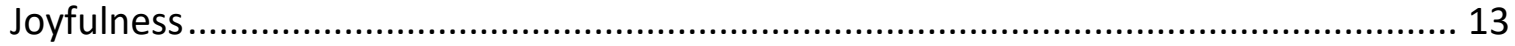

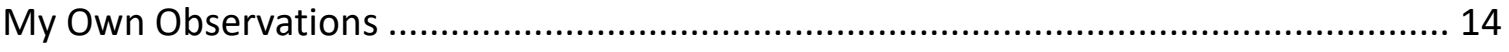

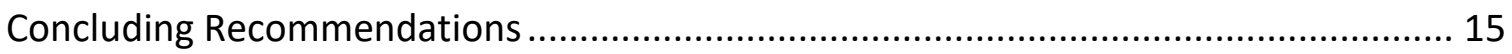

Chapter 2: 29 Practical Methods for Practice........................................................... 17

Preliminaries: the Essential Warm-Up............................................................... 19

Group 1: Most Readily Applicable Methods at Any Stage of Practice ...................... 20

1. Fermata Practice (Stop and Go Practice) ...................................................... 21

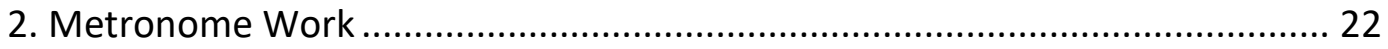

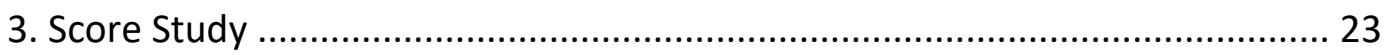

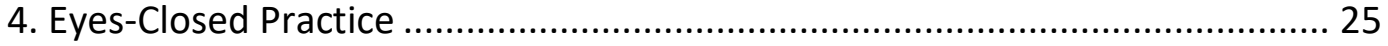

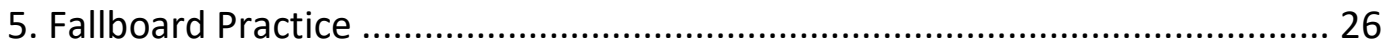

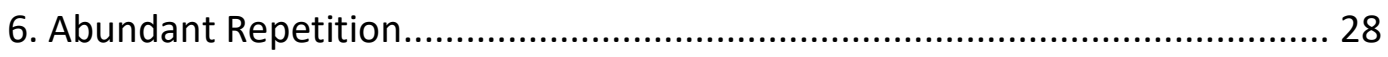

7. Repetition Aligning with Breath................................................................... 30

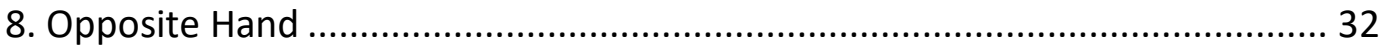

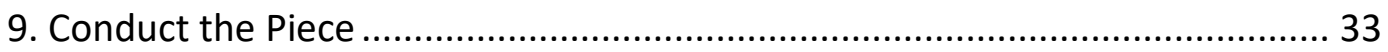

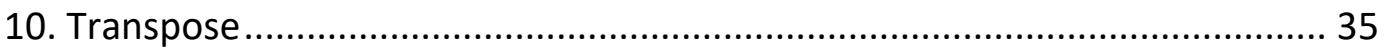

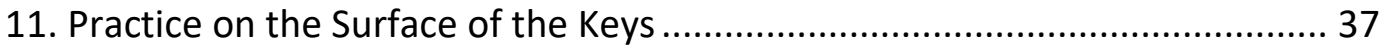

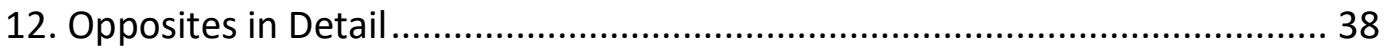

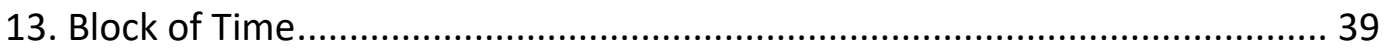

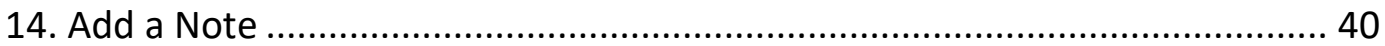

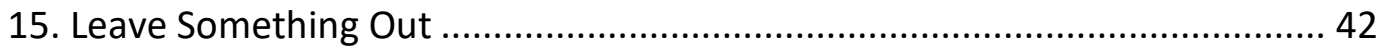




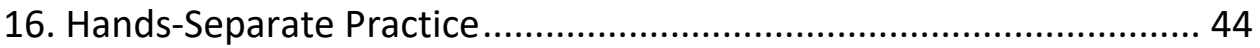

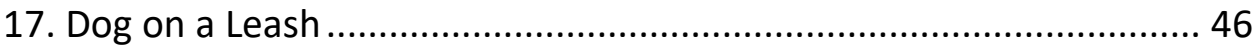

18. Record Yourself and Listen ....................................................... 48

Group 2: For the Later Stages .................................................................... 49

19. Nine Steps Process with Metronome ….......................................... 50

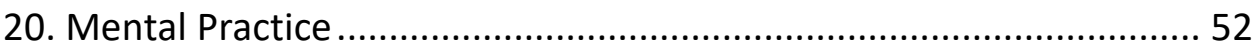

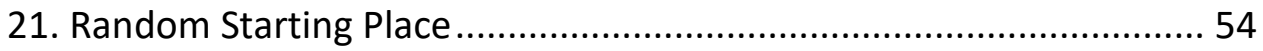

22. Play as Fast as Possible ............................................................... 56

Group 3: Techniques That Apply Best to Specific Situations.................................... 58

23. Burning Keys Exercise .................................................................. 59

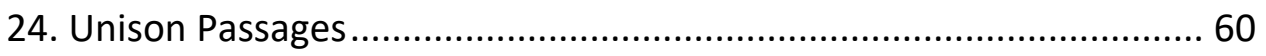

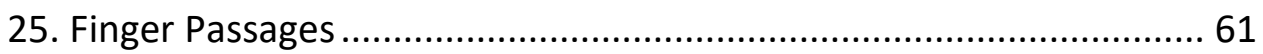

26. One-Week Method \# 1 ...................................................................... 63

27. One-Week Method \# 2 _................................................................. 65

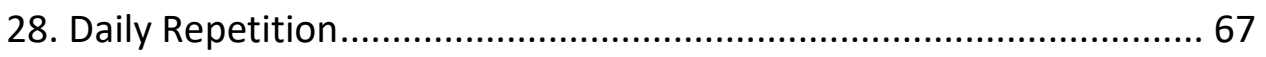

29. Beginning a New Piece ............................................................ 68

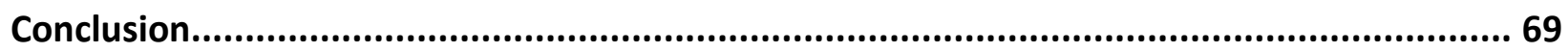

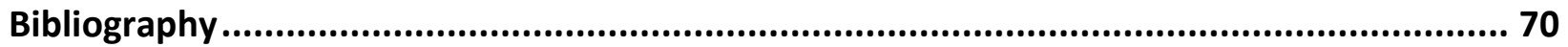




\section{Chapter 1}

\section{Introduction}

My project is for all those who wish to maintain a meaningful and lifelong practice of the piano that will reward them in any capacity. From the concert artist to the person who only plays in the privacy of their home, there are many ways to derive personal and professional fulfillment. Instead of taking the stance that piano practice be a daily requirement, this book aims at helping pianists engage in a daily practice of piano play that will continue to sustain and nurture on many levels. Heinrich Neuhaus wrote that "every performance...consists of three fundamental elements: the work performed (the music), the performer, and the instrument. Only a complete mastery of these three elements...can ensure a good artistic performance." 1

What is mastery of one's instrument? What defines piano mastery, and what type of practice leads to it? This subject occupies the minds of pianists all over the world even today, as is evidenced by the numerous blogs one finds across the internet. Opinions abound and research is often quoted, as are anecdotes from names past and present. These stories are what interest me, and what fuel my research. Many of the great, legendary performers of the past had specific practice routines and a systematic pedagogy, while others were the product of many styles or even self-taught. While it really would fill volumes to truly explore the history and development of the schools of pianistic training, this research presents a healthy sampling of ideas from the world's most celebrated pianists, in order to find common ground. I tackle the

\footnotetext{
1 Neuhaus, Heinrich. The Art of Piano Playing. London: Kahn \& Averill, 1993, p. 1.
} 
question, "What makes a master of the piano?" along with other questions that are closely related. This question leads naturally to others of equal import: "What does one do in order to remain at one's best throughout one's entire piano career?" "Is continuous lifelong improvement possible?" "What daily or regular activities are essential in order to achieve one's best at all times?" Most important for me-and the purpose of this project-is the question "How can we make it a joyful process?" This research presents a compiled list of essential ingredients which, when put into practice, can yield optimum results for pianists. In some cases I have also drawn on my personal notebook of experiences and conversations with my esteemed colleagues and teachers, performers and teachers of great talent and insight in their own right.

\section{Technique}

In the words of Vladimir Horowitz, technique "means having an absolutely clear idea of what you want and possessing the full ability for a perfect realization of it." 2 While most pianists are open to some degree about their methods, others are more secretive, and still others are misleading, exaggerating through over- or understatement how much time and effort goes into their practice. I like pianist Dmitri Paperno's view on musicianship, which includes technique in its criteria: "When outstanding talent, personality and technical perfection are combined with reliability, we are fortunate to listen to a musician of the highest class." ${ }^{3}$ To draw on a quote from the 1998 World Piano Pedagogy Convention, piano technique is a matter of "simplification, abbreviation, finding the most minimal or economical motions

\footnotetext{
${ }^{2}$ Paperno, Dmitry. Notes of a Moscow Pianist. Portland, OR: Amadeus Press, 1998, p. 175.

${ }^{3}$ Paperno, p. 100.
} 
necessary to do the job." ${ }^{4}$ I see technique along the lines of pianist Leopold Godowsky, who viewed it as a complete musical package and abhorred being called a virtuoso. ${ }^{5}$ As I shall discuss over the course of this paper, musicianship is technique and encompasses much more than mere finger dexterity. To state in advance what I believe that I have discovered in my research, and then to demonstrate it in the body of this writing, my thesis is that the best performers live and breathe music, and put it into daily practice to the highest standard possible, thus defining the path to the highest level of piano mastery. Much to the same extent that a cat is still a cat, even if you cut off its whiskers, so it is that a performer can still be a topnotch player and only perform a handful of works, styles, composers, or even concerts. What seems to matter most is the work ethic and vision of the artist. I shall now discuss various topics related to artistry, with specific artists as examples.

What about pianists with sub-par performing skills? Examples abound, but audiences, students and colleagues alike seem to forgive those who demonstrate a musicality that transcends piano technique. Arthur Rubinstein, when young, was well-known for his messy performances. However, many saw beyond the surface to what he was communicating, and when he himself made the decision to clean up his playing, he had a stellar and lifelong performing career. His innate musicality carried him through to the phase of maturity and discipline. From his example, it is clear that it was a conscious decision on his part to refine his performing skills, because he had his future path in mind. ${ }^{6}$

\footnotetext{
${ }^{4}$ http://brenthugh.com/piano/sherman.html

${ }_{5}$ Hinderer, J.G. "We Attend Godowsky's Master Class," The Musician, 38 no. 7 (July 1933): 3-4.

${ }^{6}$ https://www.commentarymagazine.com/articles/terry-teachout/whatever-happened-to-arthur-rubinstein/
} 
In the case of Johannes Brahms, we can study a completely opposite story: someone who was not in any way blessed with an easy entry into the career and who had to work hard. He was a very talented pianist who made quite a strong impression as a young performer. Yet we know from the written accounts of his students that, by the time he was in his later years, he was no longer performing as pianist and therefore no longer practicing the piano much-and his technique had gotten sloppy. Eugenie Schumann, daughter of Robert and Clara, had taken piano lessons from Brahms, and recounts that Brahms played mostly his own works by that time, and that even those were not played with technical perfection. As her teacher, he gave her this advice on playing etudes, "Play easy ones, but play them as rapidly as possible." ${ }^{7}$ We know that Brahms chose the path of the composer, so we can learn from him that the degradation in his skills was not an unfortunate problem, but the result of a career choice. It is important to note, though, that he maintained great skill as a pianist, but lost the refinement. My teacher in undergraduate studies, Dr. Robert Mayerovitch, was a student of Menahem Pressler. During one of my lessons, he shared a story of when Pressler and several other members of the piano faculty of Indiana University went to hear the legendary Sviatoslav Richter perform. The "Mephisto Waltz" by Liszt was on the program. It is widely known that the demands of this piece are such that you either play it conservatively for accuracy, or you throw caution to the wind and go for the spirit behind the music, especially at the very end. Well, in this performance, Richter missed many, many notes and one professor leaned over to Mr. Pressler and said, "Did you hear all those wrong notes?" To which Pressler replied, "Yes, but the right ones were incredible!"

\footnotetext{
${ }^{7}$ Musgrave, Michael. A Brahms Reader. New Haven: Yale University Press, 2000, p. 132
} 
It would take an unusual pianist to refer to technique as the summit of pianistic perfection, rather than as a means to an end-and this distinction makes all the difference. Musicians can only express what their technique permits, and so a pianist's work is defined by their relationship to what they can or cannot express. Based on this perspective, in answer to the opening question of this paper ("What is mastery of one's instrument?"), I would answer that possession of transcendental technique is mastery of one's instrument, because technique is what allows for complete freedom of expression. Therefore, piano mastery means that a pianist can express whatever he or she wishes through the medium of the keyboard; it is synonymous with pianism. As to the type of practice that leads to it, that is our next topic.

\section{Regimens of Practice}

While many musicians I know personally have a somewhat rigidly established personal practice routine, I am against this and was happy to see that many of the great performers are equally against having a set practice routine. Having a set routine means that you feel that you must always repeat certain activities or behaviors in a given order or under conditions that must always be present. While consistency and a measure of predictability in our work are conducive to learning and productivity, such a dependence on external factors for mental comfort risks creating a lackluster method devoid of spontaneity, freshness and flexibility.

When I sit down to practice, the last thing I want is to lose all those qualities that make the music alive; as a result, I find myself in the same camp as artists like Stephen Hough, who is fervently against any attachment to a fixed practice routine. In Safonoff's book The New 
Formula, ${ }^{8}$ a comprehensive work for the brain and fingers, he concludes with "The Student's Pentalogue," a set of five maxims. Three of these five (numbers II, III and IV) remind the pianist not to fall into a routine, not to do the same thing every day, instead making sure things are randomized or varied. I quote them here, because his staunch belief has its full effect when read verbatim:

II. Never practice in the same order, starting with the exercises, then proceeding to the studies, and finally to the pieces, but always change the order of practice every day. One day a week rest completely from the technical practicing.

III. In practising, change the order of the technical exercises every day, so as not to allow the hands to get accustomed to the same series of movements.

IV. When many repetitions of an exercise are necessary, do not always make the same number of repetitions, and choose by preference the odd $(3,5$, $7,9,11$, etc.) rather than the even numbers. ${ }^{9}$

However, one thing is quite unanimous among pianists, and that is to start the session

with the most difficult material while the mind is fresh. The focus here is not on warming up the hands or body, but on mental alertness and productivity. In fact, it is common knowledge among professionals that finger exercises and pure technical development are best saved for moments of diminished alertness, brain fog, or times following rigorous mental application. Practicing the most difficult material first (although, for safety, not immediately at rapid tempo or high volume levels) is actually the best way to get in a complete workout every time one sits at the piano. Technical demands must be analyzed and solved, interpretations solidified,

\footnotetext{
${ }^{8}$ Safonoff, Wassili. New Formula for the Piano Teacher and Piano Student. London: J \& W Chester, Ltd., 1916.

9 Safonoff, p. 28.
} 
memorization deepened, emotional reactions dealt with. As Pressler states: "Practice is about keeping confidence, gaining confidence or for new pieces, establishing confidence."10

The importance of regularity of practice, however, cannot be stressed enough. Nearly $100 \%$ of the pianists I studied, myself included, value daily practice. Even those pianists who consider themselves lazy or who do not want to practice very much will admit that daily music work is essential. In the next section I discuss hours of daily practice, which varies much more than how frequently one practices. One important distinction is to be made here: Keyboard practice or purely mental practice go hand in hand, and when an artist for whatever reason cannot gain access to a piano, mental practice takes over and is just as effective in many cases. Frederic Chiu, with whom I had one piano coaching (and, subsequently, additional musical conversations) before I performed in Carnegie Hall, developed his style of learning out of necessity. He did not have a piano in his residence when he was younger and was forced to learn pieces through mental practice. Not only has he applied his method of mental practice for years, but he also teaches it in summer intensives, where cooking is used as a metaphor for learning music, and pieces must be learned without recourse to a piano. In my own experience touring, especially in China, where during a two-and-a-half-week journey I only could practice for one hour on the day of the concert, sometimes there were as many as four days between concerts and mental practice was my only option.

\footnotetext{
${ }^{10}$ Brown, William. Menahem Pressler: Artistry in Piano Teaching. Bloomington and Indianapolis, IN: Indiana University Press, 2009, p. 89
} 


\section{Hours}

Chopin advised a student: "Once again I repeat - don't play more than two hours a day." 11 The general consensus among mature professional pianists seems to indicate no more than about five hours a day, with the norm being two to four hours of daily practice. Again, there is a distinction to be made between keyboard practice and mental practice. There seems to be a minimum number of hours a pianist must visit the keyboard in order not to lose the physical skills, but the mind can spend the entire day going over music. The greatest musicians, the masters, never really seem to stop growing musically because they are preparing their body, mind, and emotions musically throughout the day.

\section{Exercises, Etudes, Finger work, Scales}

This subject, more than most others, offers the pianistic sleuth the most varied testimonies and would be enough to make anyone uncertain of which camp to which he belongs - and to change sides at least half a dozen times! For every three pianists who swear by exercises and etudes, there is one who says that repertoire gives you everything you need to develop your technique. Of equal importance are touch and keyboard approach, which are then applied by choosing etudes and exercises which best allow such work. Many fans of Hanon and Czerny stand in one camp, while others favor more musical etudes such as those by Moszkowski; others say everything one needs can be found in Bach, and still others recommend nothing at all. In his youth, Moritz Rosenthal's teacher made him practice four hours of scales a day, plus finger studies. However, Rosenthal had a severe warning to offer in terms of such

\footnotetext{
${ }^{11}$ https://findyourmelody.com/hours-a-day-practice-piano/
} 
intense work on fast scales: "The continual practice of scales, once one has learned to play them at a fast tempo, is injurious." 12 We know that Rosenthal maintained a strong technique until the end of his career, so it is worth considering his words and looking into them deeply. His suggestions are to continue to practice scales regularly because they form an integral part of musical literature, but not for the purposes of finger development. This echoes the words of Franz Liszt, who acknowledged that scales and arpeggios form the musical vocabulary of most music and therefore cannot be completely eliminated from the practice regimen, as is evidenced in his compendium of piano exercises. However, Rosenthal does place emphasis on continued strengthening of the fourth and fifth fingers through scales in thirds and sixths.

Rosenthal credits Tausig's Gradus ad Parnassum with catapulting his technique and suggests that playing studies throughout one's entire life is important. He gives a suggested daily work routine: "Best to begin the day's work with something that engages the brain and spirit rather than merely the fingers. Work out interpretations while the mind is at its freshest-and make yourself think. When those first, most zealous thought processes have begun to calm down a bit, there is time enough left to work at purely technical studies."13 Dimitri Paperno writes that in the Russian conservatories students were assigned to play most etudes a half step lower and higher with the same fingering. He writes that this was not easy but greatly developed auditory and motor skills. ${ }^{14}$

Virtuoso performer Peter Dunhoe still practices Hanon:

"I was unwilling, but I was persuaded to do Czerny. And more specifically, or more relevantly actually, I was persuaded to do Hanon. And the reason that's

\footnotetext{
${ }^{12}$ Mitchell, Mark and Allan Evans. Moriz Rosenthal in Word and Music: a Legacy of the Nineteenth Century. Bloomington and Indianapolis, IN: Indiana University Press, 2006, p. 31.

${ }^{13}$ Henry, R. A. An analytical survey of modern trends in piano technique University of Southern California, 1945, p. 85.

${ }^{14}$ Dmitri Paperno, Notes of a Moscow pianist (Portland, OR: Amadeus Press, 1998), p. 32.
} 
become very relevant is because I do it now. And I recommend other people do it now as well. And I know plenty of my colleagues who would say that was the opposite of what we should do; that it was some kind of anti-musical experience that you don't need to do. And I don't agree with them because I have definitely felt many improvements in what I do from playing those exercises." ${ }^{15}$

The important thing with all pianists is simply not to become dependent on or overly attached to technical exercises. My own teacher made me play all my scales in octaves, thirds, sixths and tenths at a very fast tempo, and years later I heard Andras Haefliger warm up with very fast and even scales before a concert with the Wheeling Symphony. Rachmaninov is known to have played a certain A-flat major etude by Schlozer every day, ${ }^{16}$ and the reader is reminded of the advice about daily studies and etudes in Safonoff's "Student's Pentalogue" referred to earlier.

\section{Other factors}

According to Paperno, the one attitude in common among the great pianists is "An intolerance for irresponsible and careless playing." ${ }^{17}$ All truly great artists possess the highest standards in their artistry, and that accounts for the high level of achievement. Imagine Richter, who, after performing in concert with resounding success, often remained in the concert hall half the night to clean up the program he had just played and prepare the upcoming one. ${ }^{18}$

Health, be that spiritual, emotional, or physical, bears great influence on one's

performing success. We know from Chopin's biographical accounts that his performances were limited not just due to his lack of interest, but also to the state of his health. For many, the

\footnotetext{
${ }^{15} \mathrm{https}$ ://practisingthepiano.com/are-exercises-a-waste-of-time/

16 https://www.talkclassical.com/blogs/itywltmt/919-rachmaninov-pianist-youtube.html

${ }_{17}^{17}$ Paperno, p. 43.

${ }^{18}$ https://crosseyedpianist.com/tag/sviatoslav-richter/
} 
pressures of concert performances weigh too heavily on their psyche, while others seem to bask in the opportunity to perform. Pianist Ethan Iverson says: "To be comfortable on stage, or on record, you need to practice an emotional relationship to the piece. Practice routines aside, many of the best artists find that performance completes the circuit and actually enables them to play at the highest level." 19 Which means that performers must continue to perform in order to continue performing! One important aspect of maintaining sharp, top-notch performing skills means that those of us who would strive to continue to perform lifelong must maintain an active performance schedule.

The pianistic sleuth must also uncover any bad habits that will lead to injury! Damage to the hands is an almost certain death sentence for a performing career, especially damage incurred through wrong playing methods. Curiously, technique, which leads to piano mastery, can also lead to piano disaster. Scriabin is known to have permanently damaged his hand through over-practice of Liszt's Don Juan Fantasy. ${ }^{20}$ Schumann permanently injured his hand while trying to make the fourth finger more independent through an unnatural apparatus. ${ }^{21}$ In fact, there are countless horror stories of pianists injuring themselves through force, playing through pain, doing things for audience appeal, etc. I remember a pianist at a festival in Ibla, Italy, who had to withdraw due to pain and swelling in her right hand, at her fourth and fifth fingers. Having to withdraw due to pain is the result of neglect and inappropriate practice; a pianist should never experience pain while at the piano. Perhaps it may sound silly inserting this

\footnotetext{
${ }^{19} \mathrm{https}: / /$ ethaniverson.com/sonatas-and-etudes/mixed-meter-mysterium/

20 https://www.classiccat.net/scriabin a/biography.php

${ }^{21}$ https://www.nytimes.com/1981/06/14/arts/when-a-pianist-s-fingers-fail-to-obey.html
} 
into a paper on mastery, but injury is one of the pitfalls on the journey to mastery that must be avoided at all costs.

\section{Repertoire}

While some pianists have a monumental repertoire, that of others seems to be much more limited in scope. I find that neither narrowness nor vastness of repertoire suggests greater mastery of the piano. Let's consider Rachmaninov as an example. He began his career as a performing pianist at the age of 45 , out of necessity. While he obviously did not start from square one, his was not the repertoire of someone who had been concertizing since age 16 . Yet, despite his narrow repertoire, he is still remembered as one of the greatest pianists ever.

Repertoire defines a musician's artistry, because it is the final product; as such, it reveals the artist's technique and inner vision. Provided that a pianist plays convincingly, with artistry and command, he or she fulfills the calling, no matter the scope of the repertoire. What can be learned from this concept is the role that repertoire plays in developing musical mastery and pianistic proficiency. Some artists stick with tried and true pieces their entire career, while others are constantly seeking out new repertoire. Repertoire acquisition and maintenance, and the roles they play in development of technique, provide often differing views without clear answers.

In terms of the pianist's daily practice regimen, many pianists refer to the need to practice the most difficult material in one's current repertoire when first setting out to practice. This prioritizes one's work and makes possible rapid improvements by working on the material that needs one's freshest ideas and creativity. Another advantage this gives is that of solid technical practice; it also demonstrates that a person can indeed improve their technique from 
the pieces they are practicing. Many pianists that I either know or have researched recommend that various rhythmic exercises be applied to difficult passages found in pieces one is currently performing. These involve redistributing the subdivisions, placement of accents, and even applying a rubric of varied rhythms to the same notes, all with the goal of evenness. This has the advantage of having pertinent exercises at one's fingertips without sacrificing time spent on one's current repertoire, especially when time is of the essence. By contrast, American pianist Russell Sherman stated that he never practiced scales or exercises when he was young. Rather, he developed his technique through working directly on the difficulties within each piece of music.

Marguerite Long's last public performance was at age 84 . She maintained her highly developed skills until a ripe age, and the constant learning of new repertoire contributed to her ability to maintain this level. Hers is an interesting case, in that her technique was highly developed in one sense, yet lacking in variety. Her jeu-perlé style and perfect articulation came through continuous work and addition of new works to her repertoire throughout her career; however, she focused almost exclusively on French music. This had the effect of producing a style of playing that limited the depth of sound which might have come from learning more music from other traditions.

\section{Joyfulness}

Master Thay's twentieth verse from Present Moment Wonderful Moment, on sitting down to meditate, contains the lines "My body is mindfulness itself, calm and at ease, free from 
all distraction." 22 As pianists, what is the very first thing we must do in order to practice our instrument? We must sit down! Doing so mindfully is a great method for creating a space free of any negative thinking. Stress, worry, cluttered thoughts or other oppressive ideas can deliberately be cast aside while welcoming in an open and fresh feeling as we begin our work. This allows us to create a safe space within which to do our work. As we work, our practice becomes imbued with peace, concentration, and joy. We can be in touch with the very reason we choose to sit down at the piano for so much of our daily life and can feel joyful, while the result is productive and meaningful work at the piano.

\section{My own observations}

Many of my own best thoughts about pianism and musicianship come from insights gained through reading martial-arts texts, qigong ${ }^{23}$ manuals, and the like. In the "Fire" chapter of Musashi's Book of Five Rings he states: "Whoever would get to the heart of it, let him do so with conviction, practicing in the morning and training in the evening," and "Never miss morning practice." These statements come from the discipline of never missing a day in one's fitness training and I am a firm believer in applying this also as a pianist. Above all, what I have noticed is that those who maintain a faithful practice as part of their daily life, myself included, remain strong performers. When I do take time off from the piano, usually because of life's demands, my playing suffers. Menahem Pressler, a very active performer even late in life, says "To this very day, I have always loved to practice." ${ }^{24}$ It is this love of practice that makes constant development possible, for what good can come of pianists who don't want to

\footnotetext{
${ }^{22}$ Hanh, Thich Nhat. Present Moment Wonderful Moment. Berkeley, California: Parallax Press, 2006, p. 44.

${ }^{23}$ Traditional Chinese "life energy work" exercise systems

${ }^{24}$ Brown, p. 87.
} 
practice? While it is not explicitly stated, I think that, for the greatest performers, practice must by nature have something of a spiritual quality. After all, to spend that many hours a day exploring phrasing, structure, tone, physicality, emotions and more, music practice begins to distance itself from almost any other daily activity. Performers must constantly be moving upward or falling behind-either go deeper or else risk becoming shallow! In the words of Rachmaninov, upon hearing Anton Rubinstein perform: "I stored up wonderful memories, with which no others in my experience can compare. It was not so much his magnificent technique that held one spellbound as the profound, spiritually refined musicianship which spoke from every note and every bar he played..." 25

\section{Concluding Recommendations}

When I was a 19-year-old undergraduate in Cleveland, I prepared a program of the complete Etudes of Chopin. A few weeks before the concert, I told my professor that, despite all my work, I felt almost discouraged, as if I had only scratched the surface of these pieces and that the program felt unripe. His answer changed my outlook on music for the rest of my life and in many ways resembles Rachmaninov's patient and methodical approach to learning music. My teacher told me that I would feel the same at age 40, at age 50, and beyond. Music is a never-ending quest to go deeper and higher, of constant improvement and exploration. For that reason, I wish that I could include in this paper a pencil sketch of a path. Mastery of one's instrument, of music, is a path. One can be on that path already, but one can also stray from that path. Or one can continue and observe the changes. Ultimately, the essential qualities of mastery that I would include from my studies of the great pianists, with my teachers, and in my

\footnotetext{
${ }^{25}$ Harrison, 2005, p. 16
} 
own work, would be daily practice that is varied and focused, faithfulness to the highest musical standards, keyboard practice that is supplemented by mental practice, repertoire that challenges the performer at all levels (physically, emotionally, intellectually, and spiritually), and the opportunity to perform. 


\section{Chapter 2:}

\section{Practical Methods for Practice}

In this chapter you will find 29 practical approaches to practice. The complete list of 29 techniques can be found in the Table of Contents. They are divided into three main categories to help the user apply them in practice. The first group includes 17 methods that can be used from the very beginning of learning a new piece. Methods 19-22 require a higher level of familiarity and command of the material and are recommended for more advanced work on pieces already in the hands. Methods $23-29$ are more situation-specific and do not apply in all cases; after becoming familiar with them, the pianist will know when they may be applied.

After becoming comfortable with the methods that follow, pianists can choose to enrich their practice with selected individual methods; however, it is also important to realize that these practice tools can be combined. At first glance, what looks like a limited list of 29 methods actually offers much more. In many cases, two, three or more methods can be combined; everything depends upon you and your inventiveness. For example, combining EyesClosed Practice (\#4) and Repetition Aligning with Breath (\#7) becomes its own method taking each individual method in a slightly new direction. One of my favorite combinations involves Hands-Separate Practice (\#16) with Metronome Work (\#2), Abundant Repetition (\#6), Transposition (\#10), and Add a Note (\#14). The strength of these methods lies not only in each individual method, but in their versatility and compatibility with one another. These combinations can bring endless variety and utility to the practice, all while allowing deeper exploration of pianism at all levels. 
I recommend reading through the entire explanatory text for all the techniques before trying them. The very process of reading them can inspire new ideas for daily practice and lead to quicker assimilation of the methods. The more one works with them, the more they begin to recommend themselves in practice, and the more inspiration for multi-method approaches begins to inform one's practice.

Remember that many of these techniques can be combined, adding variety, depth, and multiple benefits to a single session of practice. This is actually part of the fun! 


\section{Preliminaries: the Essential Warm-Up}

Warm Up: Warming up is essential; just watch any athletic event and you will see them stretch and wake up their body with some energizing movements. In terms of piano warm-ups, we involve not just the body but also the mind. The best way to incorporate a warm-up routine is to include variety. I like to warm up with more than one type of activity.

Benefits include: Warming up brings awareness and blood flow to the body and mind, increasing our focus and reducing risk of injury.

Suggested applications: I begin each practice day by rotating a pair of two-inch copper spheres in each hand for a few minutes, then I move on to another warm-up, which is always different, at the keyboard. Feel free to mix it up by choosing a warm-up option from the list below.

How:

a. Begin immediately with the most challenging areas of your current repertoire. Use this time to fix things and create exercises based on material you find needs security, while being careful to avoid starting too fast or too loud, so as to avoid unnecessary strain.

b. Play from the classic books of exercises or etudes such as Czerny, Hanon, Liszt, Dohnanyi, etc.

c. Sight read a new piece.

d. Play something entirely enjoyable with the most beautiful sound you can make.

e. Slow practice as warm up, using anything from your current repertoire.

f. Play a variety of scales, arpeggios and chords, with awareness and not just flying fingers. 
Group 1: Most readily applicable methods at any stage of practice 
1. Fermata Practice (Stop and Go): Dr. Peter Amstutz lists this as one of his preferred methods for his students.

Benefits include:

Breaks up work into efficient chunks for the brain

Leads to clarity of the musical line $=$ how you will get to the next point

Enables execution of what is to come in the imagination first

Allows total relaxation of any tension in anticipation of coming section and nearly complete elimination of tension and fear

Suggested applications: Predetermine places at which you will stop and hold a note-or try to surprise yourself!

i. Stop at ends of phrases

ii. Stop at most logical stopping point

iii. Stop at awkward or interesting places

iv. For technical practice, employ in much shorter segments

How: Perform a selected length of music mentally, coming to a stop on a certain note. Then play the same segment at the keyboard, coming to a stop at the same place as before, when played mentally. At this point, relax all mental and physical tension. Next, mentally perform the next segment until the new stopping point and repeat the process. 
2. Metronome Work: This method was taught to me by my Grandma Ballard, who taught me from age nine to age sixteen. It is a wonderful way of increasing the security of one's playing.

Benefits include:

Security at any tempo

Ensures confident technique, clear performance

Lets one really get to know a piece very thoroughly

Suggested applications: Any piece or section requiring agility and speed

How: Set metronome at a moderato tempo such as 84 - 100. Practice at four clicks of the metronome to one note, then two clicks per note, then one click per note, then two notes per click, then three notes per click, then four notes per click, then six notes per click, then eight notes per click. 
3. Score Study: If you know how to read a book, you can study a score. All you need is a readiness to activate your imagination and your analytical mind. Get ready to look for patterns, remind yourself of things you already know, and be ready to re-think things as you delve deeper. Once you make this a regular (and preferably frequent) part of your practice, you will begin to expand the ways you can approach a score for study, along with enjoying the rewards it brings.

Benefits include:

Finding new things

Deeper awareness of the music you are playing Improving memory retention

A learning and memorization process all in its own Getting some work done away from the piano

Suggested applications: Arm yourself with a pencil or even colored pencils. Peruse your score to review things you may have already written and see if you have been ignoring those notes to yourself. This is a good time to notice reminders you might not be seeing if you are already playing from memory. If you have already absorbed them thoroughly, consider erasing them and cleaning up your score a little. 
Next, decide how you will work with the score before you begin, to give your scorestudy time a good focus.

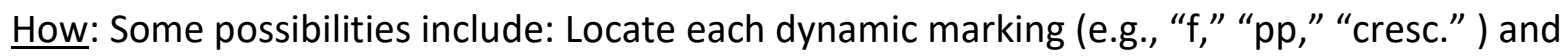
relate that to context. Locate all similar passages and see whether there are small changes made by the composer from one to the next. Focus purely on the structure of the piece by dividing the piece first into major sections and then into smaller sections.

Locate entries of subjects or themes. Count measures, insert rehearsal numbers or letters, etc. 
4. Eyes-Closed Practice: According to pianist Stephen Hough, eyes-closed practice "is probably the best technique to use for short, specific passages. I've found that it can take twenty minutes before anything gels in a tricky, leapy passage. It will be that much easier with your eyes open." 26 This technique was also a recommended manner of practice used by Leopold Godowsky and Josef Lhevinne. ${ }^{27}$

Benefits include:

Increased listening

Challenges overdependence on motor memory

Greater affinity for keyboard geography

Especially valuable for leaps and extensions

Suggested applications: Good for just about anything

How: As simple as it sounds - close your eyes and practice!

${ }^{26}$ Hough, Stephen. Rough Ideas: Reflections on Music and More. New York, NY: Picador, 2021.

${ }^{27}$ Hough, Stephen. "Random Practice Tips." Rough Ideas: Reflections on Music and More. New York, NY: Picador, 2021. 
5. Fallboard Practice: The fallboard that folds over the keys is commonly called the piano lid. Even this mechanism can be used as part of practice!

Benefits include:

Silent form of physical practice

Simplified form of physical practice

The ability to 'unleash' the musical idea free from physical restraints of the keyboard Expands listening awareness

Suggested applications: While large sections and entire pieces may be practiced this way, this technique is especially wonderful at the phrase level.

How: Close the piano lid (fallboard) and perform a selection of music with the same gestures and fingerings as if you were playing on the keys. At the same time, focus your mental energies on your musical intention. Allow the phrase to sound in your mind exactly the way you wish to hear it, while feeling that you are playing it that way.

Repeat and enjoy the process, savoring the mental exploration that comes from hearing deeply and clearly without producing physical sound. When ready, recommence playing on the keyboard, with the intent to reproduce the ideas you explored with the lid closed. 
Variation: One hand plays on the music rack or even on your lap, instead of on the fallboard, while the other hand plays on the keyboard. Not only is this a fun challenge until you get used to it, but it also allows for quite a different focus. The mind/body still must coordinate two hands, but one hand gets to have the keyboard all to itself. This also has tremendous benefits for memory retention. 
6. Abundant Repetition: Oregon University Basketball player Brady Heslip was one of the team's top three-point shooters. He had an important pre- and post-team-practice activity that strengthened and protected that ability: he successfully made 150 shots from three-point range before practice and again after practice, not going home until he had achieved 300 successful shots. For piano practice, this method achieves nearly infallible results onstage when used wisely.

Benefits include:

Rendering the performance of a passage automatic (for good or bad, so be careful!) Boost confidence and solidify memory

Suggested applications: Best for very small segments to focus on, no longer than one or two measures and as short as from note 1 to note 2 in a series. It is also advisable to use this technique multiple times, sporadically, over a long duration of weeks or months for maximum effectiveness.

How: Select passage to be practiced. Select an appropriate number of repetitions for today's practice by keeping in mind the physical, mental and time demands. For example, a short segment that takes one second to play can be played 300 times in five minutes, while a 
segment that takes even just five seconds will take a minimum of 25 minutes to play 300 times without considering intervals of time for relaxation, analysis, correction, etc.

For very short segments, consider 25, 50, 100, or 200 repetitions. For longer ones, be kind to yourself and consider something closer to 10, 20 or 50 repetitions. Do not give up! Continue until you reach your targeted number of repetitions, unless you are experiencing physical tiredness or strain. Make this as comfortable and thoughtful an exercise as possible, keeping in mind musical considerations as well so as not to train the body robotically. 
7. Repetition Aligning with Breath: A method taught me by my first teacher, Grandma Ballard. I use it to great effect in my practice and it is one of my favorites.

Benefits include:

Relaxation (physical and mental) with the additional benefit of mental focus Fluidity and pacing in complex phrases and passagework

Suggested applications: This is best done at slow to moderate tempo, with only occasional forays into fast and ultra-fast tempi. Apply to long phrases or long series of running notes. Best done in short increments of practice, for example 5, 10, or 15 minutes, until you become used to this deeper way of breathing, which draws a lot more oxygen to your brain. Don't make yourself dizzy!

How: Choose a segment and identify the starting and ending notes. Before playing, take a relaxed but deep in-breath. (Note - this is not your standard "up-beat in-breath in tempo" so common among performers. Rather, it is a slower and deeper breath that will expand your lower belly and not raise your chest. Chest breathing is shallow, whereas belly breathing is deeper and adds great length to your breathing cycle.)

Next, play from starting note to ending note, all the while exhaling gently. Do your best to coordinate ending the segment with your lungs running out of air. 
Repeat multiple times, and you will notice that not only are you becoming more relaxed, but that traveling from note to note becomes clearer, more familiar, and easier-and the phrases will gain a direction, fluidity and ease. 


\section{Opposite Hand}

Benefits include:

Deeper learning of material

Equalizes work between the two hands

Gives each hand some rest during practice

Suggested applications: This method works well in any situation, but it is especially useful when a passage has some elements that are confusing, difficult to memorize, cause anxiety, in which you risk rushing, or that just need extra attention.

How: Simply work out the passage for the opposite hand. Including a fixed fingering for the "wrong hand" will make it an even more effective exercise. Then take turns, alternating between the original hand and the opposite hand, in slow to moderate tempo until you gain confidence.

Practice in any register of the keyboard and then bring the hands together.

In this way, both hands will deeply explore and understand the passage and you will have created more pathways in the brain and body memory for successful delivery of the passage. 
9. Conduct the Piece: This is advice we perhaps all hear from our teachers at some point, but it is worth repeating because it is so beneficial.

Benefits include:

Improves inner listening

Focuses on deeper levels of the music

Challenges our sense of tempo and pulse

Highlights any irregularities in our performance tempo when we later sit at the piano to play

Incorporates our entire body in the expression of the music

\section{Suggested applications:}

Use on a day when you can't be near a piano or want to add variety to your practice routine.

Use at different stages of your learning of a piece: in the beginning stages of learning to connect with the music when you are not yet able play it up to tempo, in the active working stages to permit some progress free of the restraints of the keyboard, and in the later stages to ensure that your imagination continues to let your interpretation grow and change (avoiding getting stuck in one habitual performance). 
How:

Using your score and following all the details therein, conduct the music while mentally listening. Notice as much as you can, including your interpretive impulses and how they relate to what is on the printed page.

Do your best to be sensitive to your musical ideas and how they are similar to, or different from, your experiences playing this music at the piano. What can you learn from this exercise? What is your body telling you about your musical choices? Does your inner ear want to speed up or slow down while your body resists?

Make notes in the score afterwards. 
10. Transpose: Transposition involves the exact rendering of a passage into another key or set of identical intervals. There are pieces that I can no longer play from memory, but sections of which I can still play, not only from memory, but also in multiple keys, all due to this exercise!

Benefits include:

Intricate knowledge of a passage and solid memory retention

Exploring keyboard geography in new ways

Mental gymnastics and the challenge of a good puzzle

A growing ability to transpose

Suggested applications: Best in small doses: In small groups of notes such as two to four or five notes, transposition will allow you to reduce the passage to very manageable blocks of material. If the passage is long, consider mastering small segments of material and then linking them together in stages.

Depending on your level of comfort with transposition, you may want to choose a particular passage and write it down on staff paper first, in as many new keys as you like. This ensures proper translation into each new key.

How: Choose a segment for transposition, then decide whether you will use your original fingering for each transposition or whether you will adapt to the keyboard topography. (In 
some cases, changing fingering is absolutely necessary, while in others, your comfort level may change only due to the new black/white key-relationship changes). Never practice in a manner that causes tension!

Next, repeat the segment slowly in the original key, in a relaxed manner, with a focus on understanding the original for all its ease, difficulty, sound, keyboard geography, etc.

One this has been absorbed, begin transposing in any manner you feel works for you. (Going forwards or backwards along the circle of fifths has some advantages to either random or chromatic transposition due to the adjacent keys sharing six of seven notes. This can make both the physical and mental processes easier.)

Take your time with each transposition, working and repeating until a certain level of comfort has been achieved. While the goal is not necessarily to master each individual transposition, a gradual absorption of the passage in each key will occur.

Tempo is not as important as gaining confidence in each transposition.

Each transposition will teach you something about yourself: Is your arm free and relaxed? Are you adapting to the new keyboard geography by adding tension or by releasing tension? Does the new key change anything about the character of the musical idea? Finish by returning to the original, with the intention to integrate the new level of understanding attained from successive transpositions. 


\section{Practice on the Surface of the Keys}

Benefits include:

Greatly strengthens memory retention of a piece

A silent form of practice

Develop inner listening

A way of maintaining a piece you may be tired of but need to keep in your memory

Suggested applications: Best to perform this practice method without looking at the keys

How: Either hands together or hands separately, run through a piece by only making contact with the surface of the keys, not depressing them in the slightest. 
12. Opposites in Detail: Here, fast passages are slowed down, the left hand plays the right hand material, loud becomes soft, tragic becomes optimistic. Anything and everything is explored through its opposite.

Benefits include:

Brings freshness and variety to any practice session

Expands current physical and expressive levels of comfort with a piece or segment

Suggested applications: Works with any and all material - great for any time or situation

How:

This may be applied to one of three categories of focus: Speed (pulse), Expression (loud/soft), Articulation (release of note). Choose one focus at a time and concentrate your work as an exploration in opposite approaches to a passage or piece. For example, choose a fast passage and play it slowly as if it were a nocturne, full of depth and meaning.

Work on this passage through the contrasts of higher and lower speeds.

Next, focus on the passage in terms of sound: explore the spectrum of volume, shaping the sound to change the expressivity of the passage.

Finally, work on the passage with attention to attack/release (articulation). This will help attain clean and even playing. 
13. Block of Time: Primarily organizational in nature, this method involves pre-determining an amount of time you will dedicate to a task.

Benefits include:

Efficiency of practice

Mental relief

Organized approach when feeling overwhelmed

Suggested applications: Perfect for pieces that are sources of stress or contain some "knotty" sections that need occasional attention

How:

Before starting practice, establish a clear time frame (for example, one hour) that you will devote to a specific piece or segments of a piece. This can be a certain number of pages or a list of certain selections from a piece that are hounding you for attention.

Devote yourself entirely to your task for the timescale selected-and when it is over, move on. Do not give yourself any leeway for distractions or breaks; at the same time, do not extend the chosen time frame. This will make you both more efficient during your work and more able to let go and move on at the end of the time frame. It will also help you get to know how well you work, what your ideal working time frames are, and establish a practice based on those. 
14. Add A Note: I got this method from my Russian teacher, Dina Khudaiberdieva, who taught me after I completed my undergraduate studies. It is one of my favorite methods for sections that look like a never-ending series of notes or sequences that could be mentally or physically confusing.

Benefits include:

Mental clarity in a long section of notes

Freedom from reliance on motor memory

Ease of memorization

Suggested applications: Ideal for cadenzas or very long passages that seem intimidating or that perhaps just need clarity and a fresh perspective

How: Select a first and last note for the segment to be worked on. If the overall passage is significantly long, try subdividing the large segment into groups that make sense. This may result in segments that are uneven in number but are manageable, such as 12 notes here, 10 notes there, 18 notes in another group, etc. Next, with clear intention and avoiding any tension, play the first note and stop. Start again from note 1 and add the next note, then stop. Continue starting over, adding one note at a time to the series with each repetition. 
Variation: After working forwards, try the backwards variation in which the starting note is the final note of the passage. As in the original method, you will always play the notes in the same order as indicated on the score.

For a 12-note passage, you will start on note 12 and play it once.

Next, play notes $11-12$, in that order.

Next, play notes 10-11-12.

The starting note for each repetition builds the passage "backwards" even though the pianist is always proceeding forwards in the execution of the passage.

Combine this method with other methods, such as Fermata Practice or Dividing the Hands or Eyes Closed, to name a few. 
15. Leave Something Out: A wonderful method of simplifying the material, it involves deliberately choosing what to leave out while practicing. This can mean strategically leaving out notes, inner or outer voices, a specific hand, use of an individual finger, etc.

Benefits include: Simplification of complexities in the music or of physical nature leads to gradual mastery of material

\section{Suggested applications:}

Sections that are intellectually demanding or that contain multiple layers of texture Sections that are especially demanding or awkward physically Sections that have strange patterns that cause speed walls or blocks

How: After selecting a section for work, study the score carefully and reflect on the difficulties of that section. Are there several voices or layers going on that need their own mental attention? Is the difficulty in one hand distracting from your ability to focus on the other? Is there a pattern, or a lack of one, that defies your expectations? Is there a physical awkwardness that needs to be addressed?

Using your best judgment, begin playing a simplified form of the passage by selecting only a portion of the notes of each hand separately, and then hands together. Repeat your 
choice until you feel comfort and understanding, mentally and physically, before making changes to add notes or omit others.

As an example, for a section with very difficult sixteenth-note passagework in the right hand and rapid chord changes in the left, decide which you will first simplify. If the chords are not really difficult but distract you from something in the right-hand passagework, one suggestion is to play only the root of the left-hand chords while you focus on the right hand. You can then additionally leave out notes in the right-hand passage work as you see fit until it is properly mastered. A later adjustment could then be to simplify the right hand until you feel mentally comfortable with the rapid chord changes of the left hand. 
16. Hands-Separate Practice: I believe hands-separate practice is underrated by many. I spend a large portion of my practice time doing hands-separate work because I find it so valuable.

Benefits include:

Very helpful for memory, for technical fluency and isolating areas that need special attention

Physical and mental freshness from breaking up the work

Especially beneficial when done with frequent changes of hands

Hands-separate practice is the best security in the world for nervousness/anxiety and avoiding possible memory slips on the day of a concert.

Hands-separate practice is also a reliable method to rapidly increase speed and control without getting into trouble.

Suggested applications: Useful for any passage, phrase, segment-and even entire pieces!

How: Practice one hand at a time. The other hand can benefit from rest or can be included in the work by playing its material on your lap, on the music rack, or even "mirroring" the material of the hand played on the keyboard. (Mirroring just means that for every finger that plays on the keyboard, the same finger of the other hand will be playing elsewhere at the same time.) 
Many of the other techniques in this manual can be applied to add depth and variety to handsseparate practice. 
17. Dog on a Leash: Another preferred method of my Russian teacher

Benefits include: Finger independence and clarity in the final result

Suggested applications: While this approach is useful for just about anything you would like to sound more even in performance, it is great for awkward single-voiced passages, runs, and places that are exposed, to attain clarity and evenness.

How: To be practiced at a slow to slow-moderate tempo. In any given series of notes you will be working on, start by playing the first note twice in quick succession. After the second attack, continue depressing the note with finger weight, but without tension. You may wish to envision or imagine a release of tension at this point if that helps. With a strong attack, play the second note in the series in the same fashion: a quick double-attack, then keeping the note depressed with finger weight only. You will now have two notes depressed: the first note you played, and the second note. Release the first.

You have completed a cycle. With the second note still depressed, now play the next note in the passage in the same manner and continue this cycle until you reach the end of your selected passage.

Summary: Play note 1 quickly twice, keeping it depressed with the second strike. Play note 2 quickly twice, keeping it depressed with the second strike. Release note 1 . Play note 3 
quickly twice, keeping it depressed with the second strike. Release note 2 . Continue to the end of your selected passage. 
18. Record Yourself and Listen: When I studied in David Allen Wehr's studio, he told us to record ourselves frequently, not only before upcoming performances but at any stage of work on a piece.

Benefits include:

Opportunity for objective listening to your performance Ability to shape and refine a piece with more clarity and sometimes more quickly

Suggested applications: Works at any stage of preparation and can be used for segments of a piece as well as for entire pieces

How: While the activity itself is quite self-explanatory, recordings of yourself playing can be used in multiple ways. Depending on the sound quality, you may or may not want to include touch/voicing or issues of tone color in your analysis. However, recordings are a great way to listen for things you are not yet able to monitor while playing, as well as for correcting blind spots in your playing.

Make a checklist of concerns before listening and monitor for those, making notes where appropriate. Recordings are most honest of all about issues with time and tempo. Listen to see where you need to be more attentive to issues of rubato and pacing in your playing. You can keep individual recordings for comparison over time. 
Group 2: For the Later Stages 
19. Nine-Step Process with Metronome: This procedure requires you to establish performancetempo metronome markings for the music you wish to practice. This tempo will be manipulated mathematically for the exercise.

Benefits include:

Secure memory

Very thorough exploration of your level of confidence and mastery of a work

Suggested applications: This is a great method for larger sections or complete pieces.

How: First, establish the performance tempo of your selection. Next, identify four reduced tempos at the following percentages of performance tempo: $90 \%, 75 \%, 60 \%, 50 \%$. For example, if your performance tempo is one pulse $=144$, then your other four working tempos are: $130,108,86$, and 72.

Step 1 - Play your selection with the score as a refresher at 50\% tempo.

Steps $2 \& 3$ - Play again with the score, but once with the left hand solo and once with the right hand solo at concert tempo (100\%).

Steps 4 \& 5 - Play again, hands separately and without the score, at $90 \%$ tempo. 
Steps 6 \& 7 - Play hands together without the score at 75\% tempo, looking the entire time at only the left hand. Repeat the process, switching your attention uniquely to the right hand.

Steps $8 \& 9$ - Play hands together without the score at $60 \%$ tempo, the left hand constantly louder than the right. Repeat the process, now with the right hand constantly louder than the left. 


\section{Mental Practice}

Benefits include:

Strengthens memory and gives ultimate control and understanding of musical content

Eases nervousness associated with the fear of a memory slip

Makes for a great practice session without using the keyboard

Suggested applications: Works with anything, from the smallest series of notes or phrases to an entire piece

Try this when you are mentally alert and at another time when you are very tired, and notice the differences in effectiveness. Works best when you can also mentally hear the notes as you think them.

Mental practice in all stages of learning a piece can be done by including the score. This is a great way to ensure that all details are being absorbed and understood. Eventually, it is also of great benefit to do mental practice without the score, but this should only be done when the piece is memorized to the point that you will not experience frustration with the repeated need to consult the score.

How: Establish a goal and a field of focus for your practice. You may choose to use your hands to help remember what you are "playing," but the greatest benefit will come from only using your mind to practice. 
While involving as many senses as you can, especially mentally hearing the notes and mentally feeling the keys, practice your music at a tempo that feels comfortable for you to completely involve all notes to the degree that you have specified.

For example, if you are practicing a complex series of chords, you may want to visualize the score and allow your mind to be aware of each note from the lowest to the highest, with no concern for tempo. Or if you are practicing a fast finger passage, imagine the passage only at a comfortable tempo that allows you to see the score in your mind's eye, hear each note, and associate it with the correct finger and body movements. 
21. Random Starting Places: Grandma Ballard had a photographic memory. She did not need to sit near the keyboard or look at the score during a lesson, because she could watch it go by in her mind's eye. This exercise was her way of helping her students approximate her absorption of the score.

Benefits include:

Secures and solidifies memorization

Develops musical and technical freedom, since you will be developing the ability to play a piece from any point irrespective of what came before

Defeats reliance on motor memory

Suggested applications: Great for a self-test of your level of familiarity and mastery of a work

How: To complete this exercise you must have sufficiently organized your score for ease of execution.

You can label segments in the music with symbols, letters, numbers, also including page numbers, measure numbers, or other significant markers for reference. Take small pieces of paper the size of a large coin and write one of your organizational symbols on each. Randomize them, choose one of them at random, and begin playing at the appropriate place in the music from memory. Keep the score handy for reference. 
Another option includes making a photocopy of your score and cutting it into various labeled segments. You can draw a piece at random, begin playing it and continue from there, or try to play from a point that precedes what is on your paper, stopping at the part in the score you have drawn at random. 
22. Play as Fast as Possible. I learned this method from violinist Asya Meshberg (New York Philharmonic and Lumina String Quartet), with whom I worked and performed. She told me how it greatly helped a former student of hers on the first day of a concerto rehearsal with a conductor she had never performed with before. Not only was his tempo choice faster than her preferred tempo, but his tempo changes were also surprising and sometimes abrupt. Because she had used this method in her preparation, she had no trouble whatsoever maintaining control and musicianship at any time.

\section{Benefits include:}

Valuable test of memory

Relaxation

Technical control

Self-confidence and awareness

Very often this exercise has the effect of "ironing out the wrinkles" in a piece.

\section{Suggested applications:}

Works with anything and best when very familiar with a piece Use judiciously (and not too often). 
How: The basic choices to make before starting are tempo and whether or not you will use the metronome while completing the exercise. Keep in mind the benefits listed above, and you will understand how to choose your tempo. A good rule of thumb is to exceed concert tempo, giving your musicianship a great challenge, but not to the point that you "derail" or engage in tight, stressed or injurious practice - all of which would defeat the purpose of the exercise. 
Group 3: Techniques That Apply Best to Specific Situations 
23. Burning Keys Exercise: I developed this exercise from a qigong method intended for improving one's nervous-system connections.

Benefits include:

Accuracy in leaps

Physical quickness and improved sense of keyboard geography

\section{Suggested applications:}

Sections requiring "leaps of faith" or big shifts from one hand position to another

Best in sections that can be worked on just point $A$ to point $B$, such as a leap between two notes or two chords

In a longer section, pivot only between two at a time.

How: Select section requiring work. Hold fingers on note/chord one in a relaxed manner. Then, relax and when ready, with lightning speed move to next note or chord, touching the keytops but not actually playing the notes. Once arrived at the key and after a delay, which allows relaxation, then depress the key(s). Repeat several times attentively, to remove any tension and improve accuracy. Do not continue after first signs of muscle fatigue. 
24. Unison Passages for Two Hands: Another gem from my Russian teacher, this seemingly counter-intuitive method really works.

Benefits include: Clear unison passages

Suggested applications: Passages where left and right hand must play the identical material at displaced octaves, especially at fast tempo or involving awkward keyboard geography / exposing uneven playing between the hands

How: To sound in unison, work the passages deliberately not in unison using rhythmic displacement. Begin by playing the passage, hands together, with the right hand slightly ahead of the left, so that each note of the right hand precedes its paired note in the left. Alternatively, practice the passage in the same manner but with the left-hand notes each preceding their unison notes in the right.

Change the distance between the hands from the original, increasing or decreasing the number of octaves in between the hands. This is an additional layer that adds variety and assists with hand independence. 
25. Finger Passages: This material comes from Merrick's book on piano practice, ${ }^{28}$ which includes six different approaches to finger passages, not all of which need to be applied in any given session. They are merely varied ways of practice for a cumulatively thorough knowledge and mastery of the passages in question.

Benefits include:

Clarity and evenness

Intellectual command and authoritative memorization of selected material

\section{Suggested applications:}

Perfect for pieces or sections that have long, complex lines or patterns

Sections without any clear pattern that are difficult to memorize

Challenging finger passages and cadenzas

How: Six different methods apply:

23a: Practice hand staccato, slowly and at varying dynamic levels

23b: One-finger practice - hands separate or hands together using only one finger (for example only the 1st finger) for the entire passage. With each repetition, change the focus finger

\footnotetext{
${ }^{28}$ Merrick, Frank. Practising the Piano. Barrie \& Jenkins, 1958.
} 
23c: Play the passage in octaves (in one hand) - this will reinforce your knowledge of the notes and also serve to strengthen your octaves.

23d: Play the entire passage omitting only finger \#1; repeat omitting finger \#2, etc.

23e: Finger pedal in an exaggerated way, so that the first note drags on and overlaps the second (similar to Dog on a Leash \#17 without repeated attack)

23f: symmetrical inversion - gives the other hand the same challenges as the primary hand in the passage and also employs both sides of the brain. 
26. One-Week Method \#1 (Follow the Form): requires previous analysis of the form of the piece, to arrive at determining segments for work.

Benefits include:

Structural understanding of a work

Breaks a large work into manageable sections for efficient progress

\section{Suggested applications:}

Ideal for larger works with complex forms and multiple sections

Helps keep work progress consistent even on smaller pieces

How: Analyze a piece by dividing it into major sections and smaller segments. For longer works, start with the largest dimensions of a piece, such as ABA, or Exposition - Development Recapitulation. This will provide you with at least two or three sections. Next, identify smaller sections within those larger groups that make sense structurally. For smaller works, you can use systems, phrases, or page lengths as segments to be divided. Label your divisions with symbols, numbers, letters, images or whatever makes sense to you. Next, manage your week by establishing a way to work through the entire piece by tackling new sections every day. Your work week can be whatever you choose: a four-day, five-day, or seven-day schedule. The goal is to have a system whereby you organize your work so that it is most efficient and also relieves stress. 
For example, for my study purposes I have structurally reduced Chopin's Scherzo no. 2, op. 31 quite simply in the following ways: A-B-Development-A-Coda.

$A=a 1 b 1 c 1 a 2 b 2 c 2$

$B=d 1$ e1 $f 1 d 2$ e2 f2

$\operatorname{Dev}=f^{\prime}{ }^{\prime} e{ }^{\prime} b^{\prime}$ ' $e$ '

$A=a 3 b 3 c 3$

Coda

Within the five large sections, we see a total of six lettered segments (a - f), plus a coda, for a total of seven segments. This aligns perfectly with a work week, so in working on this piece with this method, all 'a' sections (a1 a2 a3) could be practiced on Monday. 


\section{One Week Method \# 2}

Benefits include:

Builds unity and cohesiveness into a larger piece

Structural understanding of a work

Breaks a large work into manageable sections for efficient progress

Suggested applications: Ideal for larger works with complex forms and multiple sections; Helps keep work progress consistent even on smaller pieces

How: "Monday Play your work phrase by phrase, first singing aloud each phrase on one breath.

Tuesday Play lengths of about sixteen bars at a time with suitable stopping places (each of them to be decided upon beforehand) and substituting mental rehearsals for singing, if preferred. If you sing, taking breaths now will be unavoidable, of course, but after playing your sixteen bars you should ask yourself: 'Did it go forward in one onward sweep?'

Wednesday Play about a page at a time, with the unified imaginary performance first and considered verdict afterwards.

Thursday Play lengths like exposition, development, recapitulation, coda, each complete as above.

Friday Whole movements complete as above. 
Saturday Whole movements straight through without anticipatory mental preparation, critically noticing whether one's own feelings achieve the specially desired continuity.

Sunday The whole sonata as on Saturday.

If the week's work is too closely concentrated, you could give two or three days to each of the treatments and by this multiplication spread the whole undertaking over a longer

period." 29

\footnotetext{
${ }^{29}$ Merrick, p. 33.
} 


\section{Daily Repetition}

Benefits include: Command that can only come from living with something for a long time

Suggested applications:

Passages of the highest difficulty

Challenging pieces

In preparation for a performance

How:

For smaller segments that stand out as being particularly difficult or requiring new approaches to guarantee comfort and success, you may need 200, 500 or even 1,000 cumulative repetitions. To that end, make a goal of executing a specific number of repetitions within a long-term time frame, such as 100 repetitions within 5 days. This segmentation and consistency can allow long-term benefits without over-practicing on any given day.

For pieces that are especially difficult for any reason, or before a major performance, select a sufficient time frame that will allow you to play the entire piece every day leading up to your goal. One example may be to play a piece straight through (before working on it) every day for two months. 
29. Beginning a New Piece: One of my favorite pieces of advice for beginning work on a piece, whether brand new or an old friend, comes from Dr. Peter Amstutz. He recommends working on the piece in layers: "Start with the big things, then work down in layers, eventually learning details, small things." ${ }^{30}$ Translation = simplify first! Or what I call demystifying: The initial phase of work should involve approaching the piece of music at the level of its essence, rather than a cold analysis of each note, fingering, and dynamic marking. The reasoning here is that if you know your artistic destination, you will then find the steps you need to take to get there. For example, when working on a dance piece such as a minuet, a mazurka or waltz, a good starting point is establishing the dance feel of the piece by doing some inner work (score study, listening to performances, emotional connections, tempo choices, etc.) before going to the keyboard. After initial forays into the score, the pianist can then determine a plan of work using some of the methods in this chapter.

\footnotetext{
${ }^{30}$ Conversation during lessons.
} 


\section{Conclusion}

Maintaining the skills necessary to play the piano at the highest of standards and to derive personal satisfaction requires practice. For those who wish to keep their skills throughout their entire life, I have assembled a collection of insights and practice techniques that can bring endless variety and depth, rewards and fulfillment, to your path of piano practice.

I hope that this short text can serve as a guide that will benefit many people by adding variety and depth to their practice, with the goal of deepening their level of pleasure at playing the instrument. This manual is dedicated to helping people realize that every day is a new day, that every practice session can be fresh and joyful, and that even when we think that there is no room for progress, there is always something new to try. 


\section{BIBLIOGRAPHY}

Brown, William. Menahem Pressler: Artistry in Piano Teaching. Bloomington and Indianapolis, IN: Indiana University Press, 2009.

Dunoyer, Cecilia. Marguerite Long: A Life in French Music, 1874-1966. Bloomington and Indianapolis, IN: Indiana University Press, 1993.

Eigeldinger, Jean-Jacques. Chopin: Pianist and Teacher: As Seen by His Pupils. Cambridge: Cambridge University Press, 1986.

Gerig, Reginald R. Famous Pianists and Their Technique. Washington - New York: Robert B. Luce, Inc., 1974.

Gooley, Dana. The Virtuoso Liszt. Cambridge: Cambridge University Press, 2004.

Gould, Glenn. Variations: Glenn Gould by Himself and His Friends. New York: Quill, 1983.

Hanh, Thich Nhat. Present Moment Wonderful Moment. Berkeley, California: Parallax Press, 2006.

Harrison, Max. Rachmaninoff: Life, Works, Recordings. London - New York: Continuum, 2005.

Hinderer, J.G. "We Attend Godowsky's Master Class," The Musician, 38 no. 7 (July 1933): 3-4.

Horowitz, Joseph. Conversations with Arrau. New York, NY: Alfred A. Knopf, 1982.

Hough, Stephen. Rough Ideas: Reflections on Music and More. New York, NY: Picador, 2021.

Merrick, Frank. Practising the Piano. Barrie \& Jenkins, 1958.

Mitchell, Mark and Allan Evans. Moriz Rosenthal in Word and Music: a Legacy of the Nineteenth Century. Bloomington and Indianapolis, IN: Indiana University Press, 2006.

Musgrave, Michael. A Brahms Reader. New Haven: Yale University Press, 2000

Neuhaus, Heinrich. The Art of Piano Playing. London: Kahn \& Averill, 1993. 
Newcomb, Ethel. Leschetizky as I Knew Him. New York, NY: DaCapo Press, 1967.

Paperno, Dmitry. Notes of a Moscow Pianist. Portland, OR: Amadeus Press, 1998.

Plaskin, Glenn. Horowitz a Biography. New York: Quill, 1983.

Prokofiev, Sergei. Prokofiev by Prokofiev, A Composer's Memoir. Garden City, NY: Doubleday and Company, Inc., 1979.

Reid, Daniel and Dexter Chou. The Complete Book of Chinese Health and Healing: Guarding the Three Treasures. Shambhala, 1994.

Schonberg, Harold C. The Great Pianists. New York, NY: Simon and Schuster, 1963.

Timbrell, Charles. French Pianism: A Historical Perspective, second edition, Revised and Enlarged. Portland, OR: Amadeus Press, 1999.

Websites:

Chang, Chuan C. "Fundamentals of Piano Practice." http://www.pianofundamentals.com

Classic Cat. "Biography of Alexander Scriabin."

https://www.classiccat.net/scriabin a/biography.php

Dunning, Jennifer. "When a Pianist's Fingers Fail to Obey." June 14, 1981.

https://www.nytimes.com/1981/06/14/arts/when-a-pianist-s-fingers-fail-to-obey.html

Foley, Chris. "The Collaborative Piano Blog." https://collaborativepiano.blogspot.com/

Harnish, Julian. “How Many Hours a Day Should I Practice Piano?," July 27, 2020.

https://findyourmelody.com/hours-a-day-practice-piano/.

Hough, Stephen. "Stephen Hough, pianist" http://www.stephenhough.com

Iverson, Ethan. "Mixed Meter Mysterium." https://ethaniverson.com/sonatas-andetudes/mixed-meter-mysterium/

Notes from the 1998 World Piano Pedagogy Convention: Russell Sherman, Masterclass on Mendelssohn's Rondo Capriccioso. http://brenthugh.com/piano/sherman.html 
Piano Street. http://pianostreet.com

Fitch, Graham. Practising the Piano. “Are Exercises a Waste of Time?" September 15, 2016. https://practisingthepiano.com/are-exercises-a-waste-of-time/

Talk Classical "Rachmaninov (the pianist) on YouTube" January 02, 2012

https://www.talkclassical.com/blogs/itywltmt/919-rachmaninov-pianist-youtube.html

Teachout, T. \& Lewis, M. “Whatever happened to Arthur Rubinstein?" September 3, 2015. https://www.commentarymagazine.com/articles/terry-teachout/whatever-happened-toarthur-rubinstein/

The Cross-eyed Pianist. "Recollections of Richter- part 2"

https://crosseyedpianist.com/tag/sviatoslav-richter/ 


\section{Appendix 1: Selected Exercises and Etudes:}

Beringer, Oscar. Tägliche Technische Studien. Leipzig: Peters, 1903. With more than four hundred concise exercises ranging from one page to only four bars in length, this encyclopedic work enables quick memorization of a pattern and its transposition into multiple keys. The set was created as preparation work for more difficult studies, specifically Tausig's Daily Studies. It is similar in its method to the Hanon exercises, but with more variety.

Cortot, Alfred. Rational Principles of Pianoforte Technique. Paris: France, Editions Salabert, 1930. Cortot is one of those names in piano who embody genius, and yet many say that he really struggled as a pianist. This text and group of exercises reveal much about his struggles as a pianist and, therefore, offer much in the way of teaching.

Cramer, Jean Baptiste. Fifty Selected Piano Studies. New York: G. Schirmer, 1927. Cramer's studies, while being wonderful for the fingers, are also musically developmental.

Debussy, Claude. Douze Études Pour Piano. Paris: Durand, 1916. Debussy's Etudes focus on specific elements of pianism and are both technically and artistically beneficial.

Dohnanyi, Ernst. Essential Finger Exercises for Obtaining a Sure Piano Technique. Budapest: Editio Musica Budapest, 1929. The goal of this series of 28 exercises is to reduce time spent learning too many different exercises.

Ganz, Rudolph. Exercises: Contemporary and Special. Evanston, IL: Summy-Birchard Company, 1967. This work was written in a manner similar to that of Safonoff's New Formula for the Piano Teacher and Piano Student. It is a text with musical illustrations presented in a formulaic way. Ganz's work is broken into seven chapters which highlight completely different technical studies from those found in the traditional finger-exercise books.

Ligeti, Gyorgy. Etudes pour piano. Germany: Schott, 1998. These etudes stretch the pianist interpretively and make many novel demands on technique.

MacDowell, Edward. 12 Etudes for the Development of Technic and Style, Op. 39. Boston - New York: Arthur P. Schmidt, 1975. MacDowell's set of etudes is another set of works that go beyond being just finger exercises and develop musicality. 
Palmieri, Robert. Twenty Piano Exercises. New York, Oxford University Press, 1971. This set focuses most of all on awkward pianistic challenges in multiple voices and polyrhythms, highlighting a modern trend to focus on rhythmic components of music mastery.

Safonoff, Wassili. New Formula for the Piano Teacher and Piano Student. London: J \& W Chester, Ltd., 1916. Safonoff created this method to prevent mindless practicing of exercises. His preface states: "All these exercises are not merely finger-exercises, but are at the same time brain-exercises."

Stravinsky, Soulima. The Art of Scales. New York, C. F. Peters, 1960. This set makes evident what many students who practice scales forget, namely, the need to practice scales in a musical way at all times. This work is written as preludes based on scalar writing and demands musicality. 